\title{
Diurnal cortisol and obesity in adolescents with and without Down syndrome
}

\author{
E. A. Pitchford, ${ }^{1,2}$ \\ \& D. A. Ulrich ${ }^{1}$ \\ R. E. Hasson, I,6 iD J. E. Hornyak, ${ }^{3}$ J. C. Lumeng, 4,5,6 \\ I School of Kinesiology, University of Michigan, Ann Arbor, MI, USA \\ 2 Department of Kinesiology, Iowa State University, Ames, IA, USA \\ 3 Department of Physical Medicine and Rehabilitation, University of Michigan, Ann Arbor, MI, USA \\ 4 Department of Pediatrics, University of Michigan, Ann Arbor, MI, USA \\ 5 Center for Human Growth and Development, University of Michigan, Ann Arbor, MI, USA \\ 6 School of Public Health, University of Michigan, Ann Arbor, MI, USA
}

K. E. Peterson ${ }^{6,5}$

\begin{abstract}
Background The prevalence of obesity in adolescents with Down syndrome (DS) far exceeds that in the general population. Cortisol, an adrenal hormone, can be obesogenic when dysregulated. However, the diurnal patterns of this hormone have not been examined among individuals with DS. Variations in adiposity may also mediate cortisol regulation. This study sought to examine diurnal cortisol patterns in adolescents with DS as well as associations between cortisol function and obesity.

Method A total of 32 adolescents, including I6 with DS and I6 controls with typical development (TD) of similar sex, age and Tanner pubertal stage $(P>0.05)$, participated in this preliminary study. Participants completed a dual-energy X-ray absorptiometry scan to measure body composition and collected saliva samples for cortisol measurements in the morning, afternoon and night. Linear mixed models with random intercepts and repeated measures were used to examine the daily trajectory of log-transformed cortisol concentrations between adolescents with and without DS. A second model examined the interaction between DS and presence of elevated body fatness.
\end{abstract}

Correspondence: Dr E. Andrew Pitchford, Department of Kinesiology, Iowa State University, 534 Wallace Road, Ames, IA 500II-4008, USA. Tel.: 5I5-294-3136 (e-mail: eapitch@iastate.edu).
Results Adolescents with DS had higher morning cortisol concentrations (intercept $=0.37 \mu \mathrm{g} / \mathrm{dL}$ ), but this was not significantly different than in TD (0.35 $\mu \mathrm{g} / \mathrm{dL}, P=0.16)$. Cortisol significantly declined across hours $(\mathrm{b}=-0.026 \mu \mathrm{g} / \mathrm{dL} / \mathrm{h}, P<0.00 \mathrm{I})$, but this decline also did not differ from that observed in TD $(\mathrm{b}=-0.024 \mu \mathrm{g} / \mathrm{dL} / \mathrm{h}, P=0.43)$. While cortisol levels were slightly higher among adolescents with elevated body fatness, this difference was not statistically significant $(P>0.05 ; d=0.30)$. Conclusions This study is the first to examine diurnal cortisol in DS but is limited in sample size. These preliminary findings suggest that diurnal cortisol patterns are not significantly different between adolescents with DS and TD and that cortisol levels are not associated with adiposity in this population. Despite these non-significant differences, youth with DS continue to be an 'at-risk' population for paediatric obesity in need of clinical intervention.

Keywords adiposity, cortisol, Down syndrome, endocrine, obesity, puberty

\section{Introduction}

Down syndrome is the most common genetic form of intellectual disability, with a prevalence estimated at I4.47 per Io ooo live births (Parker et al. 2010). While 
the life expectancy of persons with Down syndrome has increased substantially because of advancements in health care, morbidity and early mortality remain significantly higher than in the general population (Glasson et al. 2014; Torr et al. 2010). Addressing secondary health conditions is critical to improving long-term health outcomes in this population.

Obesity is highly prevalent among persons with Down syndrome. Approximately 55\% of youth with Down syndrome are overweight or obese (Rimmer et al. 20I0) compared with $3 \mathrm{I} \%$ of youth in the general population (Ogden et al. 20I4). Adolescents with Down syndrome have also been shown to exhibit greater body fat percentages, more total fat mass, less total lean mass and greater abdominal obesity than the general population (Bandini et al. 2012; GonzalezAguero et al. 20I i; Loveday et al. 2012; Pitchford et al. 20I8).

The foundation for obesity is energy imbalance between caloric intake and energy expenditure, but many factors contribute to the development of excess fat mass. A recent systematic review from Bertapelli et al. (2016) provided a thorough overview of potential determinants of obesity in children and adolescents with Down syndrome, including physical activity levels, dietary intake and feeding behaviours, resting energy expenditure and thyroid function. Additional physiological functions, such as leptin (Magge et al. 2008), may also play mechanistic roles in obesity for this population but are in need of further investigation.

The hypothalamic-pituitary-adrenal (HPA) axis regulates a variety of endocrine processes, including energy storage and energy expenditure (De Vriendt et al. 2009; Rodriguez et al. 2015; Adam \& Epel 2007; Bjorntorp 200I). Activation of the HPA axis increases cortisol secretion from the adrenal glands (Bjorntorp 200I; Adam \& Epel 2007; De Vriendt et al. 2009; Bjorntorp 1996). Cortisol can affect circulating energy substrate levels in the blood by increasing gluconeogenesis and lipolysis (Adam \& Epel 2007; Bjorntorp 200I; Bjorntorp \& Rosmond 2000). Visceral adipose tissue is especially sensitive to cortisol because of an increased density of glucocorticoid receptors and regulating enzymes. Glucocorticoids, including cortisol, enhance the size and number of fat cells and may play a role in the redistribution of adiposity into the visceral depot (Bjorntorp 200I; Adam \& Epel 2007;
Bjorntorp I996; De Vriendt et al. 2009; Rodriguez et al. 2015).

Hypothalamic-pituitary-adrenal axis hormones, including cortisol, are characterised by a circadian diurnal pattern with high levels in the morning and decay of output throughout the day (Pasquali et al. 2006). Multiple types of cortisol dysregulation can influence the development of obesity. First, higher cortisol levels upon waking are commonly associated with greater body mass index (BMI) (Bjorntorp 200I; Bjorntorp 1996; De Vriendt et al. 2009). Second, blunted cortisol reactivity and circadian rhythms throughout the day are associated with greater abdominal obesity (Bjorntorp 200I; Adam \& Epel 2007; De Vriendt et al. 2009; Bjorntorp 1996), as these likely result in greater total cortisol output across the day. Third, cortisol is also associated with greater insulin and leptin resistance, increased neuropeptide $\mathrm{Y}$ release and multiple markers of metabolic syndrome, thus promoting metabolic dysregulation and increased food intake (Bjorntorp 200I; Adam \& Epel 2007; Nieuwenhuizen \& Rutters 2008; Pasquali et al. 2006).

Although most research has been conducted in adults, multiple studies have identified associations suggesting that cortisol levels are higher in youth with greater adiposity (Reinehr et al. 2014; Misra et al. 2008; Guzzetti et al. 2014; Weigensberg et al. 2008, Barat et al. 2007; Veldhorst et al. 2014; Hill et al. 20II; Rosmalen et al. 2005). It should be noted that these associations are highly variable and many significant findings are limited to specific subgroups within studies (e.g. obese girls) (Hill et al. 20I I; Rosmalen et al. 2005). However, multiple large studies report the opposite direction of association with lower cortisol levels significantly associated with higher adiposity (Ruttle et al. 2013; Ondrak et al. 20II; Shirtcliff et al. 20I2; Kjölhede et al. 20I4). Independent of BMI or adiposity, cortisol has strong positive associations with insulin resistance and other markers of metabolic syndrome (Rubin et al. 2005; Adam et al. 2010; Prodam et al. 2013; Reinehr et al. 2014; Misra et al. 2008; Guzzetti et al. 20I4; Weigensberg et al. 2008; Barat et al. 2007), indicating further relevance of this hormone to overall physical health.

There is limited research on cortisol function in persons with Down syndrome (Murdoch et al. I979; Arnell et al. I996; Hestnes et al. I99I; Anneren et al.

(C) 2019 MENCAP and International Association of the Scientific Study of Intellectual and Developmental Disabilities and John Wiley \& Sons Ltd 
I; Bricout et al. 2008), but the most recent evidence suggests that persons with Down syndrome may exhibit characteristics of cortisol dysfunction that could promote obesity (Bricout et al. 2008). Significantly lower cortisol levels during rest and a blunted cortisol response to exercise were observed in young adult men with Down syndrome compared with controls (Bricout et al. 2008). However, other studies have reported normal cortisol values or differences that did not reach statistical significance (Anneren et al. I986; Hestnes et al. I99I; Arnell et al. I996; Murdoch et al. 1979). To our knowledge, no studies have tracked changes in cortisol across the day in this population, despite the known diurnal fluctuation of cortisol (Pasquali et al. 2006). Describing this diurnal pattern among individuals with Down syndrome is a first step in examining the association between this hormone and health outcomes. Furthermore, cortisol function has not been examined within the scope of obesity in Down syndrome. Given the influence of cortisol on body fat (Bjorntorp \& Rosmond 2000), the high rates of obesity and greater fat mass observed in adolescents with Down syndrome (Gonzalez-Aguero et al. 20II; Rimmer et al. 2010) may be associated with dysregulation of cortisol.

The purpose of this study was to provide a preliminary investigation of the clinical differences in diurnal cortisol patterns in adolescents with Down syndrome and with typical development.

Furthermore, this study sought to examine the independent and interactive associations between Down syndrome and elevated body fatness on diurnal cortisol function. These associations may be clinically relevant to understanding the potential contributions of cortisol dysregulation to the high rates of obesity in this at-risk population.

\section{Methods}

Participants

Participants were adolescents with Down syndrome or typical development between I2 and I8 years old and Tanner stages III to V (Marshall \& Tanner I969; Marshall \& Tanner I970). Exclusion criteria to participation included (I) documented history of hormonal insufficiency (e.g. hypothyroid); (2) use of medication that could alter metabolic functions (e.g. prednisone, central nervous system stimulants, growth hormone and thyroid hormone); (3) comorbid disease (e.g. diabetes); and/or (4) dual disability diagnosis (e.g. autism). Adolescents with and without Down syndrome had similar group averages for sex ratio, age and Tanner pubertal stage $(P>0.05)$. Matching groups on cognitive function or other developmental indices was considered but would have resulted in a prepubertal control group with different hormone profiles. Participants were recruited through Down syndrome parent support groups in Michigan and northern Ohio, family referrals and from previous study engagement with the Center on Physical Activity and Health in Pediatric Disabilities. The study was approved by the Institutional Review Board of the University of Michigan Medical School.

\section{Procedures}

\section{Puberty}

Tanner's stages of pubertal development were used to describe the maturational state of participants (Marshall \& Tanner I969; Marshall \& Tanner 1970). Pubertal stage was estimated via parental report using schematic line drawings (Morris \& Udry I980). Strong correlations have been shown in Tanner assessment between line drawings and physical exams (Morris \& Udry I980). Parental reports can provide an acceptable estimate of pubertal stage (Coleman \& Coleman 2002) and are less invasive and stressful than traditional physical assessment. Minimising stress, which directly influences cortisol levels (Bjorntorp 200I; De Vriendt et al. 2009), was critical to not skew study outcomes. Tanner stage was calculated as the average of reported stages for each participant (i.e. women: breast and pubic hair development; men: genital and pubic hair development). All participants were adolescents in Tanner stages III to V.

\section{Anthropometry}

All anthropometric measurements were conducted according to established guidelines (Lohman et al. I988). Height was measured to the nearest O.I cm and weight was measured to nearest $0.0 \mathrm{I} \mathrm{kg}$ to calculate BMI $\left(\mathrm{kg} / \mathrm{m}^{2}\right)$ and BMI percentile from the U.S. 
E. A. Pitchford et al. • Cortisol and obesity in DS

Centers for Disease Control growth reference (Kuczmarski et al. 2000).

\section{Dual-energy $X$-ray absorptiometry}

Each participant completed one dual-energy X-ray absorptiometry (DXA) scan [Lunar Prodigy Advance (DPX-IQ 240) densitometer; GE Healthcare, Madison, WI]. DXA scans provided a threecomponent (fat mass, lean body mass and bone mass) analysis of body composition. Participants wore light clothing and were positioned in a supine position with hands by the sides in a neutral position. A warm blanket was used to assist the participant with maintaining position during the scan, if needed. Paediatric software (enCore I4.0; GE Healthcare) estimated body fat percentage. Obesity was classified based on age-specific and sex-specific cut-points for elevated total body fat percentage (Freedman et al. 2009).

\section{Saliva sampling}

To measure diurnal patterns in cortisol, each participant provided three saliva samples per day for three consecutive days (nine samples total). Salivary cortisol is highly correlated with free serum cortisol (Dorn et al. 2007) and is the most common approach to naturalistic cortisol measurement. The three daily samples were scheduled respective to the participant's waking times on that day. Sampling times included (I) immediately after waking; (2) an afternoon measurement occuring when the participant returned home from school or daily activity (approximately 3:00 to 5:00 pm); and (3) immediately prior to bedtime. These time points were consistent with methodology for diurnal salivary cortisol measurement (Hoyt et al. 20I4; Keiver et al. 20I5; Ruttle et al. 2013; Shirtcliff et al. 2012). Participants were instructed not to eat, drink or brush their teeth in the $30 \mathrm{~min}$ before each sample. The participant's wake time, bedtime and saliva sample collection times were reported on a brief questionnaire.

Saliva was collected with an oral swab (Salimetrics, State College, PA). Participants placed the swab underneath the tongue to absorb saliva for 3 to $5 \mathrm{~min}$ while seated. The saturated swab was then stored in an individually numbered polypropylene vial and frozen for storage. Cortisol concentration $(\mu \mathrm{g} / \mathrm{dL})$ was measured using enzyme-linked immunosorbent assay techniques with the Expanded High Range Sensitivity Salivary Cortisol Enzyme Immunoassay Kit (Salimetrics). The assay had a lower limit of sensitivity of $0.007 \mu \mathrm{g} / \mathrm{dL}$ (Shirtcliff et al. 200I) and acceptable inter-assay (5.53\%) and intra-assay (5.I4\%) coefficients of variation (Reed et al. 2002).

\section{Statistical analysis}

All statistical analyses were conducted using SPSS 22.0 (IBM Corp., Armonk, NY) with an a priori $\alpha$ of 0.05 . Characteristics of the sample were described using descriptive statistics, Pearson's chi-square $\left(\chi^{2}\right)$ tests for dichotomous data and independent $t$-tests for continuous data with Cohen's $d$ effect sizes.

To be included in the analyses, a participant needed to have at least five valid cortisol measurements across two or more days. A total of 286 cortisol data points from the 32 participants were included in the analyses, with II (3.7\%) data points missing. The other measures (i.e. anthropometry, DXA and Tanner staging) did not have missing data. Cortisol data were not normally distributed; thus, all analyses were performed on logarithmically transformed cortisol values. However, figures were designed with raw cortisol values to aid in interpretation.

Linear mixed model (LMM) techniques were employed to examine associations between Down syndrome and adiposity on the diurnal pattern of cortisol. LMM allows for random parameters estimates, is not limited by non-independent observations (e.g. repeated measures) and does not require an equal number of data points, thus accommodating missing values. All models include random intercepts to estimate cortisol concentration at wakening and repeated time parameters to account for decreases in cortisol across the day. Hours since waking was included as a covariate in all models. Sex, age and Tanner pubertal stage were all examined as covariates but were not statistically significant in any model and were removed in favour of parsimony and maximising statistical power. Each model examined specific associations with log-transformed diurnal cortisol pattern: model I examined the presence of Down syndrome on cortisol and model 2 examined the interaction between Down syndrome and adiposity on cortisol as well as the independent presence of elevated fat mass on cortisol in 
E. A. Pitchford et al. • Cortisol and obesity in DS

adolescents with Down syndrome (model 2 b) and typical development (model 2c).

\section{Results}

The final sample included participants with valid cortisol data and all covariates $(n=32)$. Groups had similar compositions based on group averages of age, sex and Tanner pubertal stage $(P>0.05$; Table $\mathrm{I})$. Large differences were observed across all measures of body composition (Table 2), except for weight $(P=0.99, d<0.01)$. Adolescents with Down syndrome had significantly greater BMI $(P=0.00 \mathrm{I}$, $d=\mathrm{I} . \mathrm{I} 2)$, BMI percentiles $(P<0.00 \mathrm{I}, d=\mathrm{I} .35)$ and body fat percentage $(P=0.04, d=0.70)$. The proportion of participants classified as overweight
(Kuczmarski et al. 2000) and with an elevated body fat percentage (Freedman et al. 2009) were both significantly greater among adolescents with Down syndrome than with typical development $(P<0.0 \mathrm{I})$.

Cortisol followed the expected diurnal pattern with high levels in the morning and low levels at night. Model I (Table 3) showed a significant linear decrease in log-cortisol across hours of the day ( $\mathrm{b}=-0.12, \mathrm{SE}=0.02, P<0.001)$. This corresponds to an average decrease in cortisol concentration of $0.026 \mu \mathrm{g} / \mathrm{dL}$ per hour. Adolescents with Down syndrome exhibited higher morning cortisol concentration $(0.37 \mu \mathrm{g} / \mathrm{dL})$ than did adolescents with typical development $(0.35 \mu \mathrm{g} / \mathrm{dL})$. However, there were no significant differences between groups in logcortisol at the intercept $(b=-0.23, S E=0.16$,

Table I Characteristics of participants with and without Down syndrome

\begin{tabular}{|c|c|c|c|c|c|}
\hline Demographics & Total $(n=32)$ & Down syndrome $(n=16)$ & Typically developing $(n=16)$ & $\boldsymbol{P}$ & d \\
\hline Female, $n(\%)$ & $15(46.9)$ & $6(37.5)$ & $9(56.3)$ & $0.29^{\dagger}$ & \\
\hline Age (years), $M(S D)$ & $14.8(1.8)$ & $14.7(1.8)$ & $14.9(2.0)$ & $0.83^{\ddagger}$ & 0.08 \\
\hline Tanner (III/IV/V), n & $10 / 15 / 7$ & $5 / 9 / 2$ & $5 / 6 / 5$ & $0.53^{\dagger}$ & \\
\hline Caucasian, $n(\%)$ & $31(96.9)$ & $15(93.8)$ & $16(100.0)$ & $0.31^{\dagger}$ & \\
\hline
\end{tabular}

Values are mean (standard deviation) or frequency (proportion) as noted. \%, proportion of column sample; $d$, Cohen's $d$ effect size; $n$, frequency. $* P<0.05$.

†Pearson's chi-square test $\left(\chi^{2}\right)$.

¥Independent samples $t$-test $(t)$.

Table 2 Differences in body composition between participants with and without Down syndrome

\begin{tabular}{|c|c|c|c|c|c|}
\hline Body composition & Total & Down syndrome & Typically developing & $\boldsymbol{P}$ & $d$ \\
\hline Weight (kg) & $56.7(13.5)$ & $56.7(10.3)$ & $56.6(16.4)$ & $0.99^{\ddagger}$ & 0.01 \\
\hline Height $(\mathrm{cm})$ & $155.2(13.1)$ & $146.6(8.2)$ & I63.7 (II.4) & $<0.00 I^{\ddagger *}$ & $\mid .31$ \\
\hline BMI $\left(\mathrm{kg} / \mathrm{m}^{2}\right)$ & $23.6(5.0)$ & $26.3(4.1)$ & $20.8(4.2)$ & $0.001^{\ddagger *}$ & 1.12 \\
\hline BMI \%ile & $70.3(28.5)$ & $89.6(11.0)$ & $51.0(27.7)$ & $<0.001^{\ddagger *}$ & 1.35 \\
\hline Overweight/obese, $n$ (\%) & $16(50.0)$ & $13(8 \mid .2)$ & $3(18.8)$ & $<0.00 \mathrm{I}^{\dagger *}$ & \\
\hline Body fat percentage & $29.5(9.8)$ & $32.9(10.8)$ & $26.0(7.5)$ & $0.04^{\ddagger *}$ & 0.70 \\
\hline Elevated BF, $n(\%)$ & $13(40.6)$ & $10(62.5)$ & $3(18.8)$ & $0.01^{\dagger *}$ & \\
\hline
\end{tabular}

Values are mean (standard deviation) unless otherwise noted. \%, proportion of column sample; BMI, body mass index; BMI \%ile, BMI percentile based on Centers for Disease Control growth chart (Kuczmarski et al. 2000); d, Cohen's d effect size; elevated BF, proportion of column sample with elevated body fatness based on criteria outlined by Freedman et al. (2009); $n$, frequency; overweight/obese, proportion of column sample $\geq 85$ th \%ile on CDC growth chart.

$* P<0.05$, bolded.

†Pearson's chi-square test $\left(\chi^{2}\right)$.

\#Independent samples $t$-test $(t)$.

(C) 20I9 MENCAP and International Association of the Scientific Study of Intellectual and Developmental Disabilities and John Wiley \& Sons Ltd 
E. A. Pitchford et al. • Cortisol and obesity in DS

Table 3 Linear mixed model of diurnal cortisol between adolescents with and without Down syndrome (model I)

\begin{tabular}{|c|c|c|c|}
\hline Ln cortisol ( $\mu \mathrm{g} / \mathrm{dL})$ & & Model I† & \\
\hline Predictor & $\mathbf{b}$ & $95 \% \mathrm{Cl}$ & $P$ \\
\hline Intercept & -0.80 & $(-I .18,-0.4 I)$ & $<0.00 \mathrm{I}^{*}$ \\
\hline \multicolumn{4}{|l|}{ Fixed effects } \\
\hline Down syndrome (DS) & REF & & \\
\hline Typical development (TD) & -0.23 & $(-0.55,0.09)$ & 0.16 \\
\hline Hours & -0.12 & $(-0.16,-0.07)$ & $<0.00 I^{*}$ \\
\hline Time & -0.11 & $(-0.46,0.25)$ & 0.56 \\
\hline TD $\times$ Time & 0.06 & $(-0.10,0.22)$ & 0.43 \\
\hline \multicolumn{4}{|l|}{ Random effects } \\
\hline var (morning) & 0.16 & $(0.11,0.26)$ & $<0.00 I^{*}$ \\
\hline var (afternoon) & 0.28 & $(0.19,0.39)$ & $<0.00 I^{*}$ \\
\hline var (night) & 0.52 & $(0.37,0.7 I)$ & $<0.00 I^{*}$ \\
\hline Intercept & 0.14 & $(0.08,0.22)$ & $<0.00 I^{*}$ \\
\hline
\end{tabular}

DS, Down syndrome; REF, reference group for categorical comparisons; $T D$, typically developing.

$* P<0.05$, bolded.

†Model I: Schwarz's Bayesian Criterion $(\mathrm{BIC})=585.74$

$P=0.16)$ and in the slope across time $(b=0.06$, $\mathrm{SE}=0.08, P=0.43)$. The random intercept and within-subject variance of repeated measures were significant $(P<0.00 \mathrm{I})$, justifying the inclusion of random effects in the model. Diurnal cortisol trajectories across the day for adolescents with and without Down syndrome are shown in Fig. I.

To further examine the association between cortisol and adiposity, model 2 analysed the interaction between Down syndrome and elevated body fat groupings (Table 4). In total, I3 adolescents exhibited an elevated body fat percentage $(40.62 \%)$, including Io with Down syndrome $(62.50 \%)$ and three with typical development (I8.75\%). Once again, a

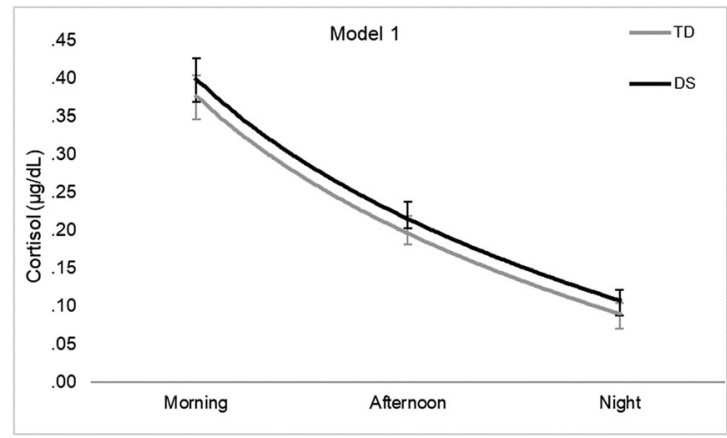

significant effect of hours since waking on log-cortisol ( $\mathrm{b}=-0 . \mathrm{I}, \mathrm{SE}=0.02, P<0.00 \mathrm{I}$ ) was observed. The main effects between disability groups $(b=-0.18$, $\mathrm{SE}=0.18, P=0.34)$ and elevated fatness groups ( $\mathrm{b}=0.12, \mathrm{SE}=0.19, P=0.50$ ) were not statistically significant nor were any of the disability by adiposity by time interactions. These relationships were confirmed to be consistent across both adolescents with Down syndrome and typical development in models $2 \mathrm{~b}$ and 2c. Diurnal cortisol patterns between groups by Down syndrome and body fatness are shown in Fig. 2. Planned post hoc pairwise comparisons between disability and adiposity groups at each time point were also not statistically significant $(P>0.05)$. Adolescents with elevated fatness had consistently higher cortisol levels, particularly in the morning, but of only a small magnitude $(d=0.30)$.

\section{Discussion}

The current study examined whether diurnal cortisol pattern was associated with the presence of Down syndrome or degree of adiposity. To the best of our knowledge, this is the first study to track diurnal cortisol in adolescents with Down syndrome. Previous studies in persons with Down syndrome have examined cortisol in a single measure (Anneren et al. 1986; Arnell et al. 1996; Hestnes et al. I991; Murdoch et al. 1979), during stress tests (Murdoch et al. 1979) and during short periods of rest and exercise (Bricout et al. 2008). Examining the diurnal cortisol patterns through multiple measurements across the day has provided more detailed information about HPA axis activity and potential associations with obesity.

A preliminary finding from this study is that adolescents with Down syndrome do not appear to

Figure I. Diurnal cortisol pattern in adolescents with and without Down syndrome (DS) (model 1). Cortisol ( $\mu \mathrm{g} / \mathrm{dL}$ ) across time points. Analyses are based on log-transformed cortisol. Post hoc linear independent pairwise corrections with Bonferroni corrections based on estimated marginal means controlling for hours since waking. ( ${ }^{\star}$ ) Differences in cortisol between adolescents with Down syndrome and typical development (TD), $P<0.05$ (no differences observed).

(C) 2019 MENCAP and International Association of the Scientific Study of Intellectual and Developmental Disabilities and John Wiley \& Sons Ltd 
E. A. Pitchford et al. • Cortisol and obesity in DS

Table 4 Linear mixed model of diurnal cortisol by Down syndrome and elevated fat mass (model 2)

\begin{tabular}{|c|c|c|c|c|c|c|c|c|}
\hline \multirow{2}{*}{$\begin{array}{c}\text { Ln cortisol }(\mu \mathrm{g} / \mathrm{dL}) \\
\text { Predictor }\end{array}$} & \multicolumn{2}{|c|}{ Model $2 \mathrm{a}^{\dagger}$ total } & \multicolumn{3}{|c|}{ Model $2 b^{\ddagger}$ Down syndrome } & \multicolumn{3}{|c|}{ Model $2 c^{\S}$ typical development } \\
\hline & $95 \% \mathrm{Cl}$ & $\mathbf{P}$ & b & $95 \% \mathrm{Cl}$ & $\boldsymbol{P}$ & b & $95 \% \mathrm{Cl}$ & $P$ \\
\hline Intercept & $-0.85(-1.30,-0.40)$ & $<0.00 I^{*}$ & -0.7 & $4(-1.23,-0.24)$ & $0.004 *$ & -1.16 & $(-1.71,-0.61)$ & $<0.00 I^{*}$ \\
\hline \multicolumn{9}{|c|}{ 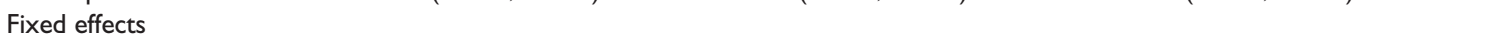 } \\
\hline Down syndrome (DS) & REF & & - & - & - & - & - & - \\
\hline Typical development (TD) & $-0.18(-0.54,0.18)$ & 0.34 & - & - & - & - & - & - \\
\hline Elevated BF\% & $0.12(-0.24,0.49)$ & 0.50 & 0.05 & $5(-0.35,0.45)$ & 0.793 & 0.21 & $(-0.45,0.88)$ & 0.53 \\
\hline Hours & $-0.11(-0.16,-0.06)$ & $<0.00 I^{*}$ & -0.10 & $0(-0.16,-0.04)$ & $0.002 *$ & -0.13 & $(-0.21,-0.06)$ & $0.001 *$ \\
\hline Time & $-0.09(-0.46,0.27)$ & 0.61 & -0.2 & $0(-0.65,0.25)$ & 0.382 & 0.06 & $(-0.46,0.58)$ & 0.822 \\
\hline DS $\times$ Normal BF $\% \times$ Time & $R E F$ & & REF & & & - & - & - \\
\hline DS $\times$ Elevated BF\% $\times$ Time & $-0.06(-0.26,0.14)$ & 0.58 & -0.02 & $2(-0.24,0.19)$ & 0.845 & - & - & - \\
\hline TD $\times$ Normal BF $\% \times$ Time & $0.02(-0.17,0.22)$ & 0.80 & - & - & - & REF & & \\
\hline TD $\times$ Elevated BF $\% \times$ Time & $0.04(-0.26,0.35)$ & 0.77 & - & - & - & -0.02 & $(-0.33,0.28)$ & 0.873 \\
\hline \multicolumn{9}{|l|}{ Random effects } \\
\hline var (morning) & $0.17(0.11,0.26)$ & $<0.00 I^{*}$ & & $8(0.03,0.19)$ & $0.026 *$ & 0.26 & $(0.15,0.45)$ & $<0.001^{*}$ \\
\hline var (afternoon) & $0.28(0.19,0.40)$ & $<0.00 I^{*}$ & 0.2 & $(0.13,0.36)$ & $<0.001 *$ & 0.35 & $(0.21,0.57)$ & $<0.00 I^{*}$ \\
\hline $\operatorname{var}($ night) & $0.52(0.38,0.72)$ & $<0.00 \mathrm{I}^{*}$ & & $(0.39,0.94)$ & $<0.00 I^{*}$ & 0.42 & $(0.26,0.68)$ & $<0.00 I^{*}$ \\
\hline Intercept & $0.14(0.08,0.22)$ & $<0.00 I^{*}$ & & $4(0.07,0.25)$ & $0.00 I^{*}$ & 0.13 & $(0.06,0.29)$ & $0.014^{2}$ \\
\hline
\end{tabular}

BF\%, body fat percentage; DS, Down syndrome; elevated BF, proportion of column sample with elevated body fatness based on criteria outlined by Freedman et al. (2009); REF, reference group for categorical comparisons; TD, typical development.

$* P<0.05$, bolded

†Model 2a: Schwarz's Bayesian Criterion $(B I C)=592.66$.

¥Model 2b: $\mathrm{BIC}=282.14$

\$Model 2c: BIC $=320.1 \mathrm{I}$

have different diurnal cortisol trajectories than adolescents with typical development. A diurnal pattern with high morning cortisol levels and a loglinear decrease in concentration across the day was observed for both groups, consistent with the expected nature of this hormone (Pasquali et al. 2006). Cortisol levels were higher in adolescents with Down syndrome at each time point compared with adolescents with typical development. However, neither the intercept $(P=0.16)$ nor the slope $(P=0.43)$ was statistically different between the groups. The lack of significant group differences is consistent with studies utilising single measurements of cortisol (Anneren et al. I986; Hestnes et al. I99I; Arnell et al. 1996; Murdoch et al. 1979). The observed diurnal pattern, characterised by a significant negative slope across hours $(P<0.00 \mathrm{I})$, confirms that repeated measurements are required to properly describe cortisol function. While Bricout et al. (2008) found significantly lower cortisol levels during rest and a blunted response to exercise among young adult men with Down syndrome, it remains unclear how these short periods of time fit into the diurnal cortisol pattern. Absolute differences in cortisol concentration between adolescents with Down syndrome and typical development in the present study, regardless of statistical significance, were larger in the morning than at the other time points. The significant differences observed by Bricout et al. (2008) all occurred in the morning, but the time from waking was not reported. Thus, the discrepancy in cortisol patterns between the two studies may be because of differences in the scope of measurement. Furthermore, the current study was conducted in adolescents while Bricout et al. (2008) examined young adult men. This suggests that there may also be systematic differences because of sex, age or pubertal status (De Vriendt et al. 2009; Tsai et al. 20I3), despite the lack of a covariate effect within the current study.

A second preliminary finding was that within both adolescents with Down syndrome and typical development, the presence of elevated adiposity was not significantly associated with diurnal cortisol 
E. A. Pitchford et al. • Cortisol and obesity in DS

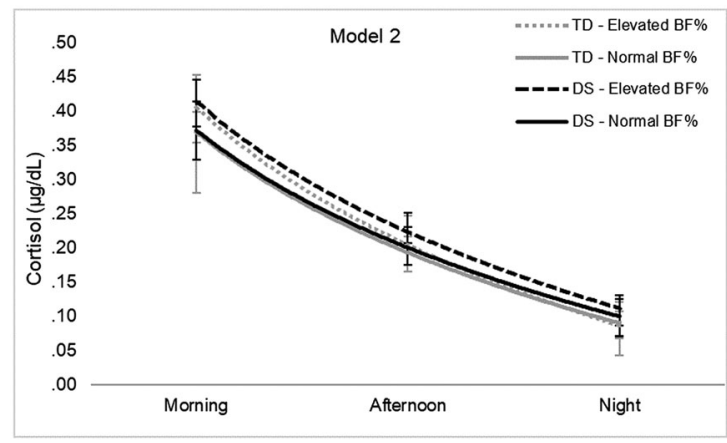

trajectory. Previous studies in typically developing children and adolescents have identified statistically significant positive associations between cortisol levels and BMI (Reinehr et al. 20I4; Rosmalen et al. 2005; Veldhorst et al. 2014), visceral adipose tissue (Misra et al. 2008), truncal fat mass (Barat et al. 2007; Weigensberg et al., 2008) and waist circumference (Guzzetti et al. 20I4; Reinehr et al. 20I4). Conversely, statistically significant inverse relationships between cortisol and BMI indices have also been reported (Shirtcliff et al. 2012; Ruttle et al. 2013; Ondrak et al. 20II; Kjölhede et al. 20I4). Additional researchers have published non-significant findings of weak positive (Hill et al. 20I I; Syme et al. 2008), inverse (Adam et al. 2010; Hill et al. 2010) or non-directional associations (Rosmalen et al. 2005; Knutsson et al. I997). Because of publication biases against nonsignificant findings, it is possible that additional examinations of cortisol and adiposity in children and adolescents are not reflected in the published literature.

A potential reason for these inconsistent associations is the variety of research designs used to examine this relationship. Across the studies mentioned earlier, cortisol was measured through a variety of mediums (e.g. saliva, blood serum, blood plasma, urine and hair), sampling frequencies (e.g. single measures and diurnal pattern) and time of day. Body composition and adiposity were also measured via BMI, total and segmental fat mass and waist circumference. Finally, the age and pubertal status of the adolescents and children studied vary widely across studies. Taken together, it is difficult to synthesise a clear correlation between cortisol function and body composition in youth as measurement, age, sex and pubertal status may all
Figure 2. Association between diurnal cortisol and adiposity in adolescents with and without Down syndrome (DS) (model 2). Cortisol ( $\mu \mathrm{g} / \mathrm{dL})$ across time points. Analyses are based on logtransformed cortisol. Post hoc linear independent pairwise corrections with Bonferroni corrections based on estimated marginal means controlling for hours since waking. ( () Differences in cortisol between adolescents with Down syndrome and typical development (TD), $P<0.05$ (no differences observed).

influence this relationship. This point is best represented by studies that found significant associations in girls but not boys (Rosmalen et al. 2005) or in only overweight children but not normal weight or obese children (Hill et al. 20II).

The adolescents with Down syndrome in the present study reflect the common health issues of this population, with over $80 \%$ of the sample categorised as overweight or obese and over $60 \%$ categorised as exhibiting elevated adiposity. These findings are consistent with recent studies reporting BMI and DXA data in adolescents with Down syndrome (Bandini et al. 20I2; Gonzalez-Aguero et al. 20I I; Loveday et al. 2012; Rimmer et al. 2010; Pitchford et al. 2018), clearly demonstrating a health disparity experienced by many individuals with Down syndrome. Despite the high prevalence of excess adiposity, co-morbid health conditions including metabolic syndrome, type II diabetes and hypertension are surprisingly absent in Down syndrome (De Winter et al. 2012; Real de Asua et al. 20I4; Draheim et al. 2002). The mechanism behind this phenomenon is unclear, but sympathetic hypoactivity and endocrine balances unique to Down syndrome have been proposed (Corsi et al. 2009; Adelekan et al. 2012; Agiovlasitis et al. 2010). Even with the lack of metabolic and atherosclerotic complications, obesity remains a serious health issue for persons with Down syndrome because of detrimental effects on mobility, independent living, community participation and quality of life (Rimmer \& Yamaki 2006). Health promotion and direct intervention efforts are clearly needed for this at-risk population (Pitetti et al. 2013; Shields et al. 2009; Rimmer et al. 2010). Study designs that allow researchers to examine relationships between health 
E. A. Pitchford et al. • Cortisol and obesity in DS

behaviours and health conditions at baseline before intervening to increase healthy behaviours may be particularly beneficial.

\section{Limitations}

The current study has a number of limitations that are important to consider when interpreting these results. First, the current sample size is small and limits both the statistical power and type of analyses that could be conducted. As such, findings from this study should be viewed as preliminary. The LMM procedures were able to converge and were appropriate for the data based on fit statistics. Interpretation of model 2, however, is limited by the small number of participants in each subgroup and may not be generalisable. It is critical to re-examine these research questions with a sample capable of producing balanced subgroups. Furthermore, the general pattern within each group was that cortisol was lower among adolescents with normal body fat, but, again, this was not significantly different. Given this trend, the high prevalence of overweight in adolescents with Down syndrome in the sample may be affecting the ability to identify differences between groups in model I. The lack of significant differences based on adiposity within adolescents with and without Down syndrome could be because of the small sample size of each group, the unbalanced proportions of obesity across groups or are reflective of an inconsistent associative relationship between cortisol and adiposity. This potential confounder should be specifically addressed in future studies.

Second, the current sample had a greater proportion of overweight participants in the group with Down syndrome. Analyses with equal representation in BMI obesity status between groups may alter results. However, matching groups for obesity status, whether through BMI or body fat (Gonzalez-Aguero et al. 20II), is only possible with a leaner group of adolescents with Down syndrome and a more overweight group of adolescents with typical development. Such a sample would then have questionable generalisability to either population. If possible, future studies may attempt to recruit unique equally distributed samples of adolescents with and without Down syndrome as well as with and without obesity to examine the independent and joint effects of these factors.
Third, adolescents were excluded from the study if they exhibited hormonal insufficiency, such as hypothyroid, to remove any potential effect on the HPA axis (Walter et al. 20I2). Hypothyroidism is a common condition among youth with Down syndrome (Bull and Committee on Genetics 20II); thus, the current sample and findings only represent adolescents with Down syndrome with normal thyroid function. Furthermore, through excluding potential participants with hypothyroidism, we may have also excluded the adolescents most likely to exhibit elevated cortisol levels (Walter et al. 2012). Despite these limitations, the current results provide useful preliminary evidence to guide future research.

\section{Conclusion}

To our knowledge, this is the first study to describe the diurnal pattern of cortisol in adolescents with Down syndrome. An extensive body of evidence from the general population supports the association between cortisol dysfunction and obesity in adults (Adam \& Epel 2007; Bjorntorp \& Rosmond 2000; Pasquali et al. 2006; Rodriguez et al. 2015; Bjorntorp 200I; Bjorntorp I996; Nieuwenhuizen \& Rutters 2008); however, this relationship is highly variable in adolescents and children (Reinehr et al. 20I4; Misra et al. 2008; Guzzetti et al. 2014; Weigensberg et al. 2008; Barat et al. 2007; Veldhorst et al. 20I4; Hill et al. 20I I; Rosmalen et al. 2005; Ruttle et al. 2013; Ondrak et al. 20I I; Shirtcliff et al. 20I2; Kjölhede et al. 20I4). Our preliminary findings suggest that diurnal cortisol levels are not significantly different among adolescents with Down syndrome compared with typically developing peers; nor between adolescents with elevated compared with normal levels of adiposity. A larger study is warranted to better analyse these relationships. Understanding the unique factors that contribute to health disparities in obesity among individuals with Down syndrome is a critical step in efforts to design and implement health promotion interventions.

\section{Source of Funding}

This research was supported by a grant from the Eunice Kennedy Shriver National Institute of Child Health and Human Development (grant number F3IHD079227) awarded to Dr Pitchford. 
Preparation of the manuscript was supported, in part, by a grant from the Office of Special Education and Rehabilitative Services (grant number H325Di I0003) awarded to Dr Ulrich.

\section{Conflict of Interest}

The authors declare that there are no conflicts of interest.

\section{References}

Adam T. C. \& Epel E. S. (2007) Stress, eating and the reward system. Physiology and Behavior 9I, 449-58.

Adam T. C., Hasson R. E., Ventura E. E., Toledo-Corral C., Le K.-A., Mahurkar S. et al. (2010) Cortisol is negatively associated with insulin sensitivity in overweight Latino youth. The fournal of Clinical Endocrinology and Metabolism 95, 4729-35.

Adelekan T., Magge S., Shults J., Stallings V. \& Stettler N. (20I2) Lipid profiles of children with Down syndrome compared with their siblings. Pediatrics 129, eI382-eI387.

Agiovlasitis S., Collier S. R., Baynard T., Echols G. H., Goulopoulou S., Figueroa A. et al. (2010) Autonomic response to upright tilt in people with and without Down syndrome. Research in Developmental Disabilities 3I, 85763.

Anneren G., Sara V., Hall K. \& Tuvemo T. (1986) Growth and somatomedin responses to growth hormone in Down's syndrome. Archives of Disease in Childhood 6I, 48 52.

Arnell H., Gustafsson J., Ivarsson S. A. \& Anneren G. (I996) Growth and pubertal development in Down syndrome. Acta Paediatrica 85, IIO2-6.

Bandini L. G., Fleming R. K., Scampini R., Gleason J. \& Must A. (20I2) Is body mass index a useful measure of excess body fatness in adolescents and young adults with Down syndrome? Fournal of Intellectual Disability Research, I050-7.

Barat P., Gayard-Cros M., Andrew R., Corcuff J., Jouret B., Barthe N. et al. (2007) Truncal distribution of fat mass, metabolic profile and hypothalamic-pituitary adrenal axis activity in prepubertal obese children. The fournal of Pediatrics 150, 535-9.

Bertapelli F., Pitetti K., Agiovlasitis S. \& Guerra-Junior G. (2016) Overweight and obesity in children and adolescents with Down syndrome-prevalence, determinants, consequences, and interventions: a literature review. Research in Developmental Disabilities 57, I8I-92.

Bjorntorp P. (1996) The regulation of adipose tissue distribution in humans. International fournal of Obesity and Related Metabolic Disorders 20, 291-302.
Bjorntorp P. (200I) Do stress reactions cause abdominal obesity and comorbidities? Obesity Reviews 2, 73-86.

Bjorntorp P. \& Rosmond R. (2000) Obesity and cortisol. Nutrition I6, 924-36.

Bricout V. A., Guinot M., Faure P., Flore P., Eberhard Y., Garnier P. et al. (2008) Are hormonal responses to exercise in young men with Down's syndrome related to reduced endurance performance? Fournal of Neuroendocrinology 20, 558-65.

Bull M. J. \& Committee On Genetics (20II) Health supervision for children with Down syndrome. Pediatrics I28, 393-406.

Coleman L. \& Coleman J. (2002) The measurement of puberty: a review. Fournal of Adolescence 25, 535-50.

Corsi M. M., Dogliotti G., Pedroni F., Galliera E., Malavazos A. E., Villa R. et al. (2009) Adipocytokines in Down's syndrome, an atheroma-free model: role of adiponectin. Archives of Gerontology and Geriatrics 48, 1069.

De Vriendt T., Moreno L. A. \& De Henauw S. (2009) Chronic stress and obesity in adolescents: scientific evidence and methodological issues for epidemiological research. Nutrition, Metabolism and Cardiovascular Diseases I9, 5II-I9.

De Winter C., Bastiaanse L., Hilgenkamp T., Evenhuis H. \& Echteld M. (2012) Cardiovascular risk factors (diabetes, hypertension, hypercholesterolemia and metabolic syndrome) in older people with intellectual disability: results of the HA-ID study. Research in Developmental Disabilities 33, I722-31.

Dorn L. D., Lucke J. F., Loucks T. L. \& Berga S. L. (2007) Salivary cortisol reflects serum cortisol: analysis of circadian profiles. Annals of Clinical Biochemistry 44, 28I4 .

Draheim C. C., Mccubbin J. A. \& Williams D. P. (2002) Differences in cardiovascular disease risk between nondiabetic adults with mental retardation with and without Down syndrome. American fournal of Mental Retardation 107, 20I-II.

Freedman D. S., Wang J., Thornton J. C., Mei Z., Sopher A. B., Pierson R. N. et al. (2009) Classification of body fatness by body mass index-for-age categories among children. Archives of Pediatrics and Adolescent Medicine I63, 805-II.

Glasson E., Dye D. \& Bittles A. (20I4) The triple challenges associated with age-related comorbidities in Down syndrome. Fournal of Intellectual Disability Research 58, 393-8.

Gonzalez-Aguero A., Ara I., Moreno L. A., VicenteRodriguez G. \& Casajus J. A. (20II) Fat and lean masses in youths with Down syndrome: gender differences. Research in Developmental Disabilities 32, I685-93.

Guzzetti C., Pilia S., Ibba A. \& Loche S. (20I4) Correlation between cortisol and components of the metabolic syndrome in obese children and adolescents. Fournal of Endocrinological Investigation 37, 5I-6.

(C) 2019 MENCAP and International Association of the Scientific Study of Intellectual and Developmental Disabilities and 
E. A. Pitchford et al. • Cortisol and obesity in DS

Hestnes A., Stovner L. J., Husoy O., Folling I., Fougner K. J. \& Sjaastad O. (I99I) Hormonal and biochemical disturbances in Down's syndrome. Fournal of Mental Deficiency Research 35, I79-93.

Hill E. E., Eisenmann J. C., Gentile D., Holmes M. E. \& Walsh D. (20II) The association between morning cortisol and adiposity in children varies by weight status. Fournal of Pediatric Endocrinology and Metabolism 24, 709-13.

Hill E. E., Eisenmann J. C., Holmes M. E. \& Heelan K. A. (2010) Morning cortisol is not associated with truncal fatness or resting blood pressure in children: crosssectional and I-2 year follow-up analyses. Fournal of Pediatric Endocrinology and Metabolism 23, I03I-7.

Hoyt M. A., Marin-Chollom A. M., Bower J. E., Thomas K. S., Irwin M. R. \& Stanton A. L. (2014) Approach and avoidance coping: diurnal cortisol rhythm in prostate cancer survivors. Psychoneuroendocrinology 49, I82-6.

Keiver K., Bertram C. P., Orr A. P. \& Clarren S. (2015) Salivary cortisol levels are elevated in the afternoon and at bedtime in children with prenatal alcohol exposure. Alcohol 49, 79-87.

Kjölhede E. A., Gustafsson P. E., Gustafsson P. \& Nelson N. (20I4) Overweight and obese children have lower cortisol levels than normal weight children. Acta Paediatrica 103, 295-9.

Knutsson U., Dahlgren J., Marcus C., Rosberg S., Brönnegård M., Stierna P. et al. (I997) Circadian cortisol rhythms in healthy boys and girls: relationship with age, growth, body composition, and pubertal development. The fournal of Clinical Endocrinology and Metabolism 82, 536-40.

Kuczmarski R. J., Ogden C. L., Grummer-Strawn L. M., Flegal K. M., Guo S. S., Wei R. et al. (2000) CDC growth charts: United States. Advanced Data, I-27.

Lohman T., Roche A. \& Martorell R. (I988) Anthropometric Standardization Reference Manual. IL, Human Kinetics, Champaign.

Loveday S. J., Thompson J. M. \& Mitchell E. A. (20I2) Bioelectrical impedance for measuring percentage body fat in young persons with Down syndrome: validation with dual-energy absorptiometry. Acta Paediatrica IoI, e49I-e495.

Magge S. N., O'neill K. L., Shults J., Stallings V. A. \& Stettler N. (2008) Leptin levels among prepubertal children with Down syndrome compared with their siblings. The fournal of Pediatrics 152, $32 \mathrm{I}-6$.

Marshall W. A. \& Tanner J. M. (1969) Variations in pattern of pubertal changes in girls. Archives of Disease in Childhood 44, 29I-303.

Marshall W. A. \& Tanner J. M. (1970) Variations in the pattern of pubertal changes in boys. Archives of Disease in Childhood 45, 13-23.

Misra M., Bredella M. A., Tsai P., Mendes N., Miller K. K. \& Klibanski A. (2008) Lower growth hormone and higher cortisol are associated with greater visceral adiposity, intramyocellular lipids, and insulin resistance in overweight girls. American fournal of Physiology, Endocrinology and Metabolism 295, E385- 3392.

Morris N. M. \& Udry J. R. (I980) Validation of a selfadministered instrument to assess stage of adolescent development. Fournal of Youth and Adolescence 9, 27I-80.

Murdoch J. C., Giles C. A., Grant J. K. \& Ratcliffe J. G. (1979) Hypothalamic-pituitary-adrenocortical function in adults with Down's syndrome. Fournal of Mental Deficiency Research 23, 157-62.

Nieuwenhuizen A. G. \& Rutters F. (2008) The hypothalamic-pituitary-adrenal-axis in the regulation of energy balance. Physiology and Behavior 94, 169-77.

Ogden C. L., Carroll M. D., Kit B. K. \& Flegal K. M. (20I4) Prevalence of childhood and adult obesity in the United States, 20II-20I2. The fournal of the American Medical Association 3II, 806-I4.

Ondrak K. S., Mcmurray R. G., Hackney A. C. \& Harrell J. S. (20II) Interrelationships among changes in leptin, insulin, cortisol and growth hormone and weight status in youth. Fournal of Clinical Research in Pediatric Endocrinology 3, 22-8.

Parker S. E., Mai C. T., Canfield M. A., Rickard R., Wang Y., Meyer R. E. et al. (2010) Updated national birth prevalence estimates for selected birth defects in the United States, 2004-2006. Birth Defects Research Part A: Clinical and Molecular Teratology 88, 1008-16.

Pasquali R., Vicennati V., Cacciari M. \& Pagotto U. (2006) The hypothalamic-pituitary-adrenal axis activity in obesity and the metabolic syndrome. Annals of the New York Academy of Sciences 1083, II I-28.

Pitchford E. A., Adkins C., Hasson R. E., Hornyak J. E. \& Ulrich D. A. (2018) Association between physical activity and adiposity in adolescents with Down syndrome. Medicine and Science in Sports and Exercise 50, 667-74.

Pitetti K., Baynard T. \& Agiovlasitis S. (2013) Children and adolescents with Down syndrome, physical fitness and physical activity. Fournal of Sport and Health Science 2, 4757.

Prodam F., Ricotti R., Agarla V., Parlamento S., Genoni G., Balossini C. et al. (2013) High-end normal adrenocorticotropic hormone and cortisol levels are associated with specific cardiovascular risk factors in pediatric obesity: a cross-sectional study. BMC Medicine II, I-I.

Real De Asua D., Parra P., Costa R., Moldenhauer F. \& Suarez C. (2014) A cross-sectional study of the phenotypes of obesity and insulin resistance in adults with Down syndrome. Diabetes and Metabolism fournal 38, 464$7 \mathrm{I}$.

Reed G. F., Lynn F. \& Meade B. D. (2002) Use of coefficient of variation in assessing variability of quantitative assays. Clinical and Diagnostic Laboratory Immunology 9, I235-9.

Reinehr T., Kulle A., Wolters B., Knop C., Lass N., Welzel M. et al. (20I4) Relationships between 24-hour urinary free cortisol concentrations and metabolic syndrome in

(C) 2019 MENCAP and International Association of the Scientific Study of Intellectual and Developmental Disabilities and 
E. A. Pitchford et al. - Cortisol and obesity in DS

obese children. The fournal of Clinical Endocrinology and Metabolism 99, 239I-9.

Rimmer J. H. \& Yamaki K. (2006) Obesity and intellectual disability. Mental Retardation and Developmental Disabilities Research Reviews 12, 22-7.

Rimmer J. H., Yamaki K., Lowry B. M., Wang E. \& Vogel L. C. (2010) Obesity and obesity-related secondary conditions in adolescents with intellectual/developmental disabilities. Fournal of Intellectual Disability Research 54, 787-94.

Rodriguez A. C. I., Epel E. S., White M. L., Standen E. C., Seckl J. R. \& Tomiyama A. J. (2015) Hypothalamicpituitary-adrenal axis dysregulation and cortisol activity in obesity: a systematic review. Psychoneuroendocrinology 62, 30I-I8.

Rosmalen J., Oldehinkel A., Ormel J., De Winter A., Buitelaar J. \& Verhulst F. (2005) Determinants of salivary cortisol levels in IO-I2 year old children; a populationbased study of individual differences. Psychoneuroendocrinology 30, 483-95.

Rubin D. A., Mcmurray R. G., Hackney A. C. \& Harrell J. S. (2005) The relationship between leptin, metabolic hormones, exercise and body composition in adolescents. Fournal of Pediatric Endocrinology and Metabolism 18, I07382.

Ruttle P. L., Javaras K. N., Klein M. H., Armstrong J. M., Burk L. R. \& Essex M. J. (2013) Concurrent and longitudinal associations between diurnal cortisol and body mass index across adolescence. Fournal of Adolescent Health 52, 73I-7.

Shields N., Dodd K. J. \& Abblitt C. (2009) Do children with Down syndrome perform sufficient physical activity to maintain good health? A pilot study. Adapted Physical Activity Quarterly 26, 307-20.

Shirtcliff E. A., Allison A. L., Armstrong J. M., Slattery M. J., Kalin N. H. \& Essex M. J. (20I2) Longitudinal stability and developmental properties of salivary cortisol levels and circadian rhythms from childhood to adolescence. Developmental Psychobiology 54, 493-502.

Shirtcliff E. A., Granger D. A., Schwartz E. \& Curran M. J. (200I) Use of salivary biomarkers in biobehavioral research: cotton-based sample collection methods can interfere with salivary immunoassay results.

Psychoneuroendocrinology 26, I65-73.

Syme C., Abrahamowicz M., Leonard G. T., Perron M., Pitiot A., Qiu X. et al. (2008) Intra-abdominal adiposity and individual components of the metabolic syndrome in adolescence: sex differences and underlying mechanisms. Archives of Pediatrics and Adolescent Medicine 162, 453-6I.

Torr J., Strydom A., Patti P. \& Jokinen N. (2010) Aging in Down syndrome: morbidity and mortality. Fournal of Policy and Practice in Intellectual Disabilities 7, 70-81.

Tsai S. L., Seiler K. J. \& Jacobson J. (2013) Morning cortisol levels affected by sex and pubertal status in children and young adults. Fournal of Clinical Research in Pediatric Endocrinology 5, 85-9.

Veldhorst M. A., Noppe G., Jongejan M. H., Kok C. B., Mekic S., Koper J. W. et al. (20I4) Increased scalp hair cortisol concentrations in obese children. The fournal of Clinical Endocrinology and Metabolism 99, 285-90.

Walter K. N., Corwin E. J., Ulbrecht J., Demers L. M., Bennett J. M., Whetzel C. A. et al. (20I2) Elevated thyroid stimulating hormone is associated with elevated cortisol in healthy young men and women. Thyroid Research $\mathbf{5}$. https:/thyroidresearchjournal.biomedcentral.com/ articles/IO.II86/1756-66I4-5-13

Weigensberg M. J., Toledo-Corral C. M. \& Goran M. I. (2008) Association between the metabolic syndrome and serum cortisol in overweight Latino youth. The fournal of Clinical Endocrinology and Metabolism 93, I372-8.

Accepted I August 2019

(C) 2019 MENCAP and International Association of the Scientific Study of Intellectual and Developmental Disabilities and John Wiley \& Sons Ltd 